\title{
Towards an Archaeological Theory of Infrastructure
}

\author{
Darryl Wilkinson ${ }^{1}$
}

Published online: 29 December 2018

(C) The Author(s) 2018

\begin{abstract}
Infrastructure makes up a considerable portion of the material culture that archaeologists study. Whether measured in terms of spatial extension or just sheer mass, infrastructural entities are often among the biggest artifacts that archaeologists encounter in the field. Yet there is no overarching theoretical framework for the archaeological study of infrastructure, and its different varieties tend to be treated in a rather piecemeal fashion. This article therefore seeks to lay some foundations for a more theoretically unified approach to infrastructure within the discipline. It offers a general definition or infrastructure, as well as a basic typology. The typology presented is fourfold, encompassing (1) static infrastructure (e.g., terraces, harbors and storehouses), (2) circulatory infrastructure (e.g., highways, canals, aqueducts, and sewers), (3) bounding infrastructure (e.g., palisades, ditches, and corrals), and (4) signaling infrastructure (e.g., lighthouses and beacons). By analogy with more heavily theorized categories such as urbanism, it is suggested that infrastructure should be a topic of global comparative analysis within archaeology and its allied disciplines.
\end{abstract}

Keywords Infrastructure $\cdot$ Politics $\cdot$ Roads $\cdot$ Storehouses $\cdot$ Fortifications $\cdot$ Terraces

\section{Introduction}

In one sense, archaeologists have always studied infrastructure. We could hardly say the discipline has ignored things like roads, aqueducts, field systems, or canals over the years (Morrison 2015). But as a category of theoretical analysis, infrastructure has to date only had limited purchase within archaeological circles. Consider here the stark contrast with "urbanism." Over many decades, archaeologists have devoted considerable intellectual and material resources to understanding cities, and so urbanism is often treated as a theoretically loaded term. There are long-running debates about how to

Darryl Wilkinson

daw89@cam.ac.uk

1 McDonald Institute for Archaeological Research, University of Cambridge, Downing Street, Cambridge CB2 3ER, UK 
define urbanism, when and how it begins, and whether modern cities differ fundamentally from their ancient counterparts (Cowgill 2004; Yoffee 2009). Of course no consensus has emerged on the answers to any of these questions, but it is nonetheless widely acknowledged that it is important to ask them. Urbanism is therefore a topic that is global in scope, driven by a comparative approach and which requires a multimillennia temporal perspective. Yet there has never been an equivalent research program for infrastructure. ${ }^{1}$ Thus, no extensive archaeological literature exists on the question of how infrastructure should be defined, when it emerges in historical time, or how its more modern varieties might be different from those of antiquity.

It is true that individual archaeological discourses exist for some kinds of infrastructure, yet not for the category as a whole. For example, storage facilities have long received archaeological attention, but often tied to the larger theoretical issue of "surplus." Similarly, archaeologists frequently study roads and highways, but they are normally subsumed under conceptual lenses like "landscape" or "movement" (e.g., Snead et al. 2009). Elsewhere, due to the influence of Karl Wittfogel (1957), irrigation systems have had a considerable impact on archaeological thought - but mainly as a subsidiary factor in explaining the origins of complex society. As a rule then, most archaeological studies of infrastructure only deal with one particular variety. Moreover, archaeologists sometimes produce globally comparative analyses of particular kinds of infrastructure - for example Scarborough and Lucero's (2010) analysis of ancient water management systems in semitropical environments - but without actually using the word infrastructure itself. By contrast, it would seem strange if archaeologists were to study monumental tombs, temples, palaces, residential neighborhoods, markets, and public spaces, without ever uniting all these phenomena under the general analytical rubric of urbanism. Yet this is effectively how infrastructure appears in most archaeological narratives. Highways, aqueducts, bridges, sewers, and terraces are widely referenced phenomena in themselves, but absent any overarching theory. Thus my main concern here is to present infrastructure as a general category, one that subsumes a wide range of material phenomena, and thereby allows us to engage in its comparative analysis across time and space.

Outside of archaeological circles, the last decade has witnessed a great deal of interdisciplinary interest on the topic of infrastructure, drawing together work by ethnographers, geographers, political scientists, and literary scholars (e.g., Anand 2012; Elyachar 2010, 2012; Harvey 2012; Larkin 2008, 2013; Redfield 2011; Robbins 2007; Star 1999; Von Schnitzler 2013). Perhaps the earliest archaeological attempt to grapple with the topic was Palus' $(2010,2011)$ analysis of public utilities in the city of Annapolis during the twentieth century - but it is only in the last few years that we have seen a (modest) increase in the number of archaeological studies that explicitly foreground infrastructure as a theoretical lens. Like Palus' (2010) study of Annapolis, Smith (2016) centers her theoretical discussion on the infrastructure of urbanized societies specifically, while Hauser (2015) frames his account of infrastructural

\footnotetext{
${ }^{1}$ Why infrastructure has received so little attention as a category in comparison to urbanism is ultimately a historiographical question, and beyond the scope of this article. However, the central role that cities have played in the Western ideal of civilization would seem the obvious place to start. In Western thought, to be civilized has long implied being urban; and etymologically the words "civilization" and "city" share a common Latin origin (Jennings 2016, pp. 7-11). Infrastructure does not carry the same weight of moral connotations.
} 
networks around the colonial-era plantations on the island of Dominica in the Caribbean. Although they use archaeological methods, these studies also take recent historical periods as their main subject matter. With respect to hydraulic infrastructures specifically, a deeper chronological perspective is offered in Morrison's (2015) research on South Asia and in Ertsen's (2016) work on Mesopotamia.

Since it appears that infrastructure is becoming a topic of growing concern, both within archaeology and without, the present article sets out to develop a theory of infrastructure as an object of archaeological analysis. By theory, I mean a general definition of infrastructure, as well as a basic typology. It should be noted that in some archaeological commentaries, typologies would be excluded from the realm of the strictly theoretical. For instance, Schiffer (1988) understands theories in terms of universal explanatory concepts that invoke "unobservable" phenomena. For example, the germ theory of disease explains many illnesses in terms of the effects produced by unobservable (i.e., microscopic) organisms. However, such approaches still leave a significant conceptual gap between abstract explanatory paradigms and "raw" data. Indeed, typologies and definitions are among the main conceptual frameworks that mediate between the data we collect and the ultimate interpretations that are generated (Tomášková 2005). In this respect, Johnson (2010, p. 2) offers a much broader definition of theory as "the order we put facts in" — so for him, "even the most basic act of description and classification is immediately theoretical" (Johnson 2013). Hodder (2004, p. 2) adopts a similarly liberal stance when he says that, "theoretical discussion involves defining terms, stating positions, setting up categorical boundaries." My approach follows these more comprehensive definitions of theory, seeing it as effectively the entire conceptual apparatus that surrounds the production, organization, and interpretation of data. That said, it does not necessarily follow that all theory operates at the same "level" (see Smith 2011, pp. 167-173), and so typologies can reasonably be understood as a more fundamental kind of theory than explanations. For instance, the germ theory of disease only makes sense given a categorical distinction between microorganisms and macroorganisms, and it develops more refined explanatory power through further taxonomic subdivisions (i.e., viruses, bacteria, fungi, and protozoa). Put another way, to categorize is not necessarily to explain, but explanation often seems to depend on categories of some kind. Certainly it is difficult to conceive of many of the classic archaeological paradigms without the underlying taxonomies upon which they depend. What would be left of neo-evolutionism without its basic categories of bands, tribes, chiefdoms, and states? Or world systems theory, absent the spatial typology of core, periphery, and semi-periphery? So although typologies are not explanatory per se, in my view they remain a practical necessity for much (perhaps all?) theorization.

But is it really necessary for archaeologists to develop theories of infrastructure specifically? For some, the fact that others in the humanities and social scientists are increasingly debating infrastructure would itself be a sufficient reason for archaeologists to weigh in on the topic. Interdisciplinarity is often presented as an inherent good, and it is logically dependent on there being overlapping areas of interest and shared keywords across different scholarly fields. As archaeologists, we often argue that the unique contribution of our field resides in our close attention to material culture, as well as our unusually deep chronological perspectives. Thus geographers, literary scholars, and ethnographers who are interested in infrastructure would benefit from the alternative perspectives and datasets that we archaeologists bring to the table. Indeed, there are 
signs that the lack of an archaeological voice in infrastructure studies has already fostered a rather shallow temporal framing. As an example, consider the following statement by the ethnographer Elyachar (2012, p. 113, my emphasis):

Infrastructure in a traditional sense refers to roads, railroads, water, electricity and gas supply, sewage, telephone lines, and the like. Without roads and without railroads, goods cannot get to market and local economies cannot enter the global market. The state has been a key player in the provision of infrastructure since the nineteenth century.

I suspect many archaeologists would raise an eyebrow at the claim that state provision of infrastructure only became significant during the $1800 \mathrm{~s}$. That said, I do not believe Elyachar's statement is meant to be taken as a considered historical claim. It simply reflects the fact that virtually all work on infrastructure in the humanities and social sciences is an avenue to understanding some aspect of modernity. In fact, Mitchell (2014, p. 438) lays out the link between the two in quite explicit terms when he says that, "technological infrastructures appear to shape the successive epochs of modernity." Older scholarship was accustomed to thinking of modernity in terms of new ideas (e.g., secularism, individualism, nationalism) or major socio-economic transformations (e.g., urbanization, industrialization, bureaucratization). The present shift towards infrastructure thus provides an opportunity to approach modernity through the palpable realities of wires, pipes, steel girders, and the like; very much in line with the Zeitgeist of new materialist theory. It is not surprising then that the growing literature on infrastructure has virtually no interest in, and thus very little to say about, "premodernity." The multi-millennia timescales habitually used in archaeology thus seem an obvious way to remedy this.

Moreover, although many ethnographic, geographic, and literary studies explicitly frame their work on infrastructure as "new materialist" in tenor, they are still primarily talking about discourses on infrastructure, rather than the physical entities themselves. In other words, their main empirical focus is on what people say about infrastructures (whether spoken or written down). A properly archaeological theory of infrastructure would instead approach it as a kind of artifact - something that we can analyze independently of written accounts - just as we do with pottery or lithics. Of course, this does not imply we should ever ignore relevant textual evidence; rather it means that we will find ourselves offering little of value if we simply seek to replicate the discursive analyses practiced in other disciplines, which frankly have much more material of this sort to work with. Archaeologists have a great deal to offer the interdisciplinary discourse on infrastructure, but interdisciplinarity requires explicit bridging efforts. If we do not frame our work on infrastructure in a fashion that makes it legible to other scholars, archaeologists will likely continue as marginal players in such conversations.

Finally, a justification for an explicitly typological approach arises from the simple fact that as a discipline we already study infrastructure, and in doing so we necessarily invoke tacit typologies. Indeed, I would suggest virtually every statement about material culture invokes taxonomic orders, and this is true regardless of scale. So we regularly think about lithic assemblages in typological terms, invoking words like burin, scraper, projectile point, 
handaxe, and so on - just as we habitually subdivide ceramics into the basic functional triad of serving, cooking, and storage vessels. The same is true for much larger artifactual entities as well. We are implicitly applying a typology when we opt for the label "road," instead of "street" or "trail." And to call something a "village" is inevitably a taxonomic proposition; for it implies it is not a city, town, camp, or farmstead. My point then is not so much that taxonomy is good, but rather it is inescapable. The only difference is how much explicit reflection and critique has occurred with respect to the taxa that are being deployed. It seems to me that we should always make our conceptual frameworks explicit rather than implicit, since by doing so we can more readily examine them — and if necessary, revise them or even reject them.

\section{Defining Infrastructure: Some Initial Parameters}

In the non-archaeological research on infrastructure, which is almost entirely concerned with the issue of modernity, the state is always a major presence. In fact, it is very difficult to imagine the modern state without the physical infrastructures upon which it is based (Schouten 2013). Thus it seems implicit in many accounts that infrastructure is effectively the materialization of the state itself. I prefer not to make such a claim, mainly because it forces us to subordinate the definition of infrastructure to the broader category of the state. In other words, if only states have infrastructure, then we cannot define infrastructure without first having an agreed definition of the state. But there has never been a consensus among archaeologists on what the term "state" actually means (Pauketat 2007, pp. 143-146), and I therefore think it unproductive to hitch the category of infrastructure to another term that is itself so thorny and contentious. Moreover, many of the kinds of infrastructure I will outline in this article can clearly be identified in societies that very few archaeologists would want to describe as states, even by the most liberal of definitions. In Neolithic Britain for example, we have the remarkable raised wooden walkways (e.g., the Sweet Track, dated via dendrochronology to $3807 \mathrm{BC}$ ) that were constructed across stretches of marshland, sometimes up to two kilometers in total length (Hillam et al. 1990). This would clearly qualify as transport infrastructure by any standard, and would have required considerable community resources of wood and labor for its physical creation. In a similar vein, we also have substantial rice paddies being constructed in the Yangtze drainage from the early Neolithic (ca. 5000-4500 BC) onwards (Zheng et al. 2009). If Neolithic infrastructures are nothing unusual, then drawing a necessary link between infrastructure and the state seems invalid. For the same reasons, I do not follow Smith's (2016, p. 2) view that infrastructure comes into being as a direct consequence of urbanism.

However, I do agree with Smith's (2016, p. 2) definition of infrastructures as “landscapescale connectivities consisting of elements more extensive than one household can construct, maintain and use by itself," insofar as the term infrastructure implies some kind of physical apparatus that requires the labor input of supra-household communities. ${ }^{2}$ How one defines a

\footnotetext{
${ }^{2}$ By "supra-household communities" I do not necessarily mean formal or permanent institutions that manage labor on a large scale. For instance, a group of households might collectively agree to pool their labor for a shared project on a short-term basis, which would itself constitute a "supra-household community," albeit an ad hoc one.
} 
household is not entirely straightforward of course (see Pluckhahn 2010), but since our concern here is specifically with labor inputs, let us say that "households" typically have access to labor pools comprising fewer than 20 adult persons. Supra-household communities would then be those with a labor pool in excess of this level. On such grounds, we might reasonably exclude storage facilities such as the domestic food bins found at many of the Pre-pottery Neolithic sites of the Near East (e.g., Çatalhöyük), since they appear not to exhibit any form of warehousing beyond the level of individual houses, or at most, extended family groups (Bogaard et al. 2009). But there is nonetheless a considerable gap between a supra-household level of labor pooling and the extent of labor organization that we would normally associate with a state. I do not think putting a strict figure on it is particularly helpful, but in impressionistic terms, most of us probably imagine "states" to command labor pools on the order of thousands of individuals (at least). Yet even if infrastructures can exist without states, it is clear that infrastructure often becomes more important as societies become more "state-like." For some of the largest pre-modern polities, like the Inca, Roman, and ancient Chinese empires, the extent of infrastructural investment was often quite remarkable; drawing on labor pools involving many millions of individuals. So we can maybe imagine infrastructure without the state, but not the state without infrastructure. ${ }^{3}$ Of course, if we define infrastructure as the product of supra-household maintenance and construction efforts, it is only to be expected that it becomes more important as the scale of social organization increases. But we should not just think of infrastructure as passively reflecting the scale of the human communities that create it. In turn, infrastructure often actively promotes human organization at a larger scale - uniting dispersed households and settlements through their integration with physical entities like irrigation systems and roads.

In general, I also exclude residential architecture from my definition of infrastructure. The rationale for not including ordinary houses is fairly obvious - if infrastructure implies a supra-household level of labor organization, not just for construction but also for its use and maintenance, then most physical dwellings would not qualify. Very large houses however, especially those associated with elites, and which we might be inclined to call "palaces," obviously draw upon much larger labor pools than the more modest residential structures of the masses. It is also true that states often build residential complexes that are not necessarily intended for elites, but are nonetheless much larger than typical households - common examples of which include barracks, prisons, and monasteries. Indeed, one might ask why any large architectural installation should not be considered as a form of infrastructure. What about churches and temples, for instance? Or even schools and universities? After all, we could technically insist that the Great Pyramid at Giza is basically an elaborate storage facility (for human remains), as are tombs in general. In the end it would be possible to consider any of these structures as infrastructure if one so desired. But I am less interested here in setting up rigid theoretical categories, and more with heuristic utility. Moreover, I am concerned to prevent "infrastructure" from gobbling up all other categories, becoming so broadly applicable that its theoretical value suffers.

Undoubtedly, both architecture and infrastructure are part of the wider "built environment," and on a physical level, they are often interwoven. For instance, the wires of modern electricity grids now reach into virtually every building on the

\footnotetext{
${ }^{3}$ A similar point could be made about urbanism: infrastructure can exist without cities, but all cities probably need some kind of infrastructure to support their dense populations.
} 
landscape. But I nonetheless think it useful to draw a conceptual distinction between infrastructure and architecture. In commonsense terms, architecture usually implies structures with enclosed and interior spaces (i.e., buildings), whereas infrastructure often entails open-air structures that sprawl across the landscape (e.g., roads, canals, bridges, aqueducts). Perhaps another possible way of making the distinction is to say that architecture is that aspect of the built environment that is primarily oriented towards directly accommodating people, whereas infrastructure is the part dedicated to accommodating things, resources, and waste. Storehouses and silos, despite being closed buildings, are therefore "infrastructures" because they mainly house objects rather than people. Similarly, aqueducts and sewers are structures that contain water (i.e., resources) and effluent (i.e., waste), rather than humans. But it is always a matter of emphasis, rather than an absolute difference - after all, humans are still occasional visitors to storehouses and sewers. In other cases, a built structure might host a great deal of human activity, but heavily mediated through things like vehicles (including ridden animals). For instance, Harbors and roads are commonly human-occupied spaces, but they are primarily designed to accommodate persons contained within ships and wagons. In line with this argument, the distinction between closed buildings and open-air landscape structures seems more of a second-order characteristic. Architecture, because it is human-oriented, is more likely to be closed over, since humans often need or want shelter for many activities. But some structures like stadiums, plazas, and arenas are primarily focused on accommodating humans, despite being open to the air, and would thus fall under architecture. ${ }^{4}$

In the end, it is impossible to ever draw an absolute line between architecture and infrastructure. Instead, the categorical distinction represents a useful heuristic for thinking about the different ways in which we might approach the built environment as an artifact. The architecture/infrastructure distinction thus provides two different frameworks for analyzing the built environment, rather than representing two separate components from which it is comprised. For example, architecture often draws in questions of esthetics, and architecture itself is often treated as a form of art. However, it would be strange to look at roads or sewers as "art." This is not to say one could not do so-in theory anything can be considered art-it just might not be particularly illuminating. Elsewhere, one might consider the esthetic qualities of a bridge (i.e., an architectural analysis) or instead choose to examine its engineering characteristics (i.e., an infrastructural analysis), even though it would be the same material artifact in either case. The architecture/infrastructure distinction is not therefore intended to strictly separate the built environment into its constituent elements; rather it draws out different aspects of the built environment as a whole, and so encourages different kinds of questions.

Finally, I suggest that infrastructures are normally fixed, immobile entities. Of course, anything can be moved given enough time and effort, so this is necessarily a

\footnotetext{
${ }^{4}$ The fact that infrastructure is primarily designed for things also means it has a tendency to attract human activities that are either illicit or undesirable (at least from the perspective of the powerful). In a modern city, the best places to look for illegal forms of visual culture (i.e., graffiti) are along railway tracks, and around tunnels, bridges, and underpasses. Homeless communities also cluster in similar areas, especially in underground facilities like subways and storm drains. It is not surprising that highly marginalized-and often dehumanized - groups of people would seek to appropriate the built spaces designed around things, given that access to more human-centered architecture is often denied them.
} 
relative criterion. But it is useful to exclude most objects that are routinely portable and malleable in human hands (e.g., small containers, clothing, handheld tools, and weapons). In sum then, infrastructures are broadly defined as (1) large and immovable technological apparatus that are distinguishable from more portable objects, (2) which imply supra-household communities in their construction and ongoing use, but (3) excluding most architectural structures, such as residences and other human-oriented buildings. At a more specific level, I see infrastructures as falling into four general categories, based on their primary functions and physical characteristics - a quadripartite taxonomic schema that consists of (I) static, (II) circulatory, (III) bounding, and (IV) signaling infrastructures. This proposed typology will be discussed in detail in the following section.

\section{Steps Towards an Initial Typology}

\section{Static Infrastructure}

Static infrastructures are those designed to maintain spaces of environmental stasis. In other words, they create zones of relative stability, which contrast with their more changeable surroundings. ${ }^{5}$ An obvious modern example would be freezing and refrigeration facilities, which provide a consistently low-temperature environment for the storage and transport of perishable goods, regardless of how much the exterior temperature might fluctuate. In general, storage facilities of all kinds are paradigmatic examples of static infrastructure, and while electric refrigeration is a very recent invention, spaces with deliberately controlled temperature and humidity have a very long history. A secondary benefit of storehouses is that they make it easier to quantify and stocktake supplies, and so plan for their eventual use and redistribution.

Granaries are probably one of the most widespread, and most ancient forms of static infrastructure. For instance, Proto-cuneiform texts from Mesopotamia during the Uruk III and Uruk IV periods repeatedly refer to the centralized redistribution of grain rations (Paulette 2016). Although virtually no physical evidence for these storage facilities has ever been found, the written record clearly implies their existence. Given that most classic definitions of urbanism emphasize the aggregation of large numbers of people not engaged in food production (e.g., Childe 1950), it seems reasonable to assume that ancient cities could not have existed without some kind of institutionalized food storage. Or at least the particular kinds of urban communities that we see in the Near Eastern Bronze Age could not have survived without granaries to provide for the considerable numbers of non-farming artisans and officials. As D'Altroy and Earle (1985, pp. 190-191) argue, storage facilities are essentially a means of synchronizing the availability of goods with their use, as well as a mechanism for concentrating prime forms of wealth in the hands of the authorities. Non-food resources were therefore subject to stockpiling by ancient states too, especially high-value materials that were important in long-distance exchange relations. While food storage is especially

\footnotetext{
${ }^{5}$ In this context, static does not mean immobile, as this is a general feature of all infrastructure. The term static is used in the sense of "promoting stasis" (i.e., maintaining a three-dimensional space in which environmental conditions are kept relatively constant).
} 
dependent on controlled environmental conditions, many non-food materials also benefit from being kept in facilities that are protected from the elements (e.g., textiles and metals subject to corrosion). Some recent research indicates that for the ancient Near East at least, centralized storage of cereal grains is an older phenomenon than the warehousing of wealth items and craft products (e.g., Philip 2008, pp. 14-15), although there is no reason to assume this was true everywhere.

Agricultural terraces should also be placed within the category of static infrastructure, since their function is to stabilize the environmental context in which crops are grown. Wet terraces, such as those used in rice cultivation (i.e., paddies) first appear in East Asia after $5000 \mathrm{BC}$, perhaps only 1000 years or so following the initial domestication of rice itself (Zheng et al. 2009). A rice paddy is effectively a deliberately flooded field, which provides a suitable environment for semiaquatic crops during the early stages of growth that follow planting. One major form of environmental stability that such terraces promote is kinetic, in that their retaining walls considerably reduce the extent of soil erosion caused by the effects of water flow. The prehistoric Andes provide another well-known case of extensive ancient terracing systems, noted for their capacity to create thermal microclimates, something especially important in mountainous contexts where ecological variation is extreme with respect to changes in elevation. Effectively, terraces allow certain crops to be grown at altitudes where this would otherwise be impossible. Studies of prehistoric terraces in the Colca Valley in Peru, for example, have shown the importance of terraces as a means to promote water retention in planting soils, which in turn affects ambient temperatures (Guillet 1987). And at the site of Copacabana in Bolivia, the Incas' manipulation of microclimates through terraces allowed them to extend maize cultivation to an altitude of $3900 \mathrm{~m}$ asl (D'Altroy 2000), even though maize normally experiences sharply reduced yields or non-viability above the $3500 \mathrm{~m}$ asl mark (Sandweiss and Richardson 2008, p. 96). However, the microclimatic effects of terracing do not simply relate to higher absolute temperatures, but also the promotion of cyclical thermal stability. The central Andes typically experience sharp diurnal variations in temperature, and one of the primary impediments to growing warm-weather crops at extreme altitudes is therefore the cold nights. It is significant that the limit for (unterraced) maize cultivation (i.e., $3500 \mathrm{~m}$ asl) is close to the elevation at which nocturnal temperatures regularly drop below freezing, a result of the fact that maize is not a very frost-resistant crop (Skarbø and VanderMolen 2016). It has long been understood that water is an important store of thermal energy in natural environments (hence the overnight frigidity of deserts), and moisture therefore mitigates diurnal temperature fluctuations. Thus the favorable microclimates that Andean terraces create are more to do with fostering thermal stability as opposed to higher temperatures in general.

There are other forms of static infrastructure beyond storehouses and terraces. Harbors, for instance, are also very much intended to maintain a stable environment in an area otherwise beset by environmental flux (i.e., coasts). But in the case of a harbor, the goal is kinetic stability, rather than suppressing variations in temperature or humidity. Effectively, the breakwaters of a harbor shield the vessels inside from the large waves produced during high winds and storms - thus the variation in wave amplitude outside the harbor is high (kinetic instability), while the variation in wave amplitude inside the harbor is relatively low (kinetic stability). In historical terms, harbors are largely a consequence of having vessels that are too large to be regularly 
pulled onto the land. The most ancient forms of water transport, like canoes and rafts, could simply be dragged onto the shore for offloading and onloading, or when they were not in regular use. However when vessels reached a certain size, they needed to be permanently kept in water after being launched. In maritime zones where shipping became important at a relatively early stage, such as the Mediterranean, we see the first large seagoing vessels appear around the end of the Early Bronze Age (ca. 3300$2000 \mathrm{BC}$ ), and become increasingly more common thereafter (Gould 2011) - a phenomenon that drove the need for greater investment in maritime infrastructure such as harbors. Rock-cut harbors appeared in the Levant by the Late Bronze Age, and with the advent of the great maritime trading societies of the Phoenicians and the Greeks by the early first millennium $\mathrm{BC}$, harbor construction seems to have proceeded at an everaccelerating rate (Blackman 1982).

As zones of relative environmental stability, static infrastructures generally rely on two kinds of stabilizing technologies. The first are "energy barriers" that are designed to interrupt any external energy sources that might cause internal change. For example, the breakwaters of a harbor absorb and displace the kinetic energy of the waves that hit them, while the walls and roofs of a storehouse absorb and radiate back the solar energy they receive from the sun. The second kind of stabilizing structures are those designed to control the movements of internal fluids. An obvious example of this are the spillways used to regulate the depth of water in a rice paddy, and the drainage canals that are often associated with Andean terraces. Controlling airflow is often just as important as controlling water, and ventilation facilities are a common feature of static infrastructures too, especially in storehouses where they are used to regulate temperatures and to prevent the build up of excessive humidity. Inca storehouses often incorporated small openings at their bases in order to maintain good airflow, reflecting the importance of stockpiling perishable goods within the Inca political economy (see Fig. 1).

The frequency and scale of static infrastructures seems to be broadly linked to processes of "intensification." For example, the agricultural terraces of the ancient

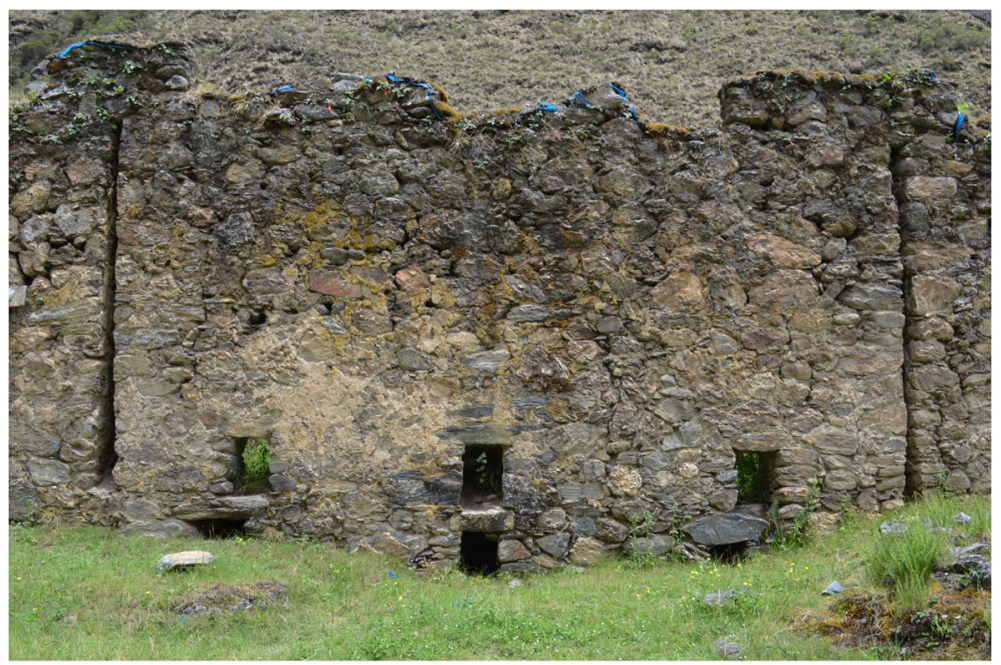

Fig. 1 A series of Inca storehouses near Cusco (Peru), with ventilation apertures visible along their lower exterior walls 
Andes required no sophisticated new technologies for their construction; simply being layers of soil and gravel retained by stone masonry. Instead they were a product of the increasing reliance on maize agriculture during later prehistory. Evidence from stable isotope studies on skeletal remains (Finucane 2009) and palynological samples from lake sediments (Chepstow-Lusty et al. 2009) indicates that maize only started to dominate the diet of highland populations around the middle of the first millennium $\mathrm{BC}$, despite being already present in the Andes for millennia. Most heavily terraced landscapes seem to have originated in the early first millennium AD, and are associated with rising populations and the desire for imperial Andean states to produce large quantities of food and beer for feasting events (Pearsall 2008, pp. 116-117). Often, the different kinds of static infrastructure seem to grow in tandem as well. As Kim (2014) discusses for the Middle Mumun Period ( $c a .800-300$ BC) in the Korean Peninsula, there is a simultaneous shift towards intensified rice paddy agriculture alongside the emergence of public storage facilities. Not only is there an almost fivefold increase in total storage volume, but the location of the facilities shift from domestic interiors to exterior spaces, implying shared supra-household management of food resources (Kim 2014). Likewise, the expansion of harbor facilities is also linked to intensification processes, although here the direct stimulus is increased traffic in bulk goods rather than agricultural production per se. For example, as ancient Rome became increasingly dependent on Egyptian grain imports to feed its population, the nearby port facilities at Ostia were substantially upgraded, while massive warehouses called horrea were used to store the shipped produce. Under the emperor Trajan, a new 32-ha hexagonal harbor basin was constructed within the Portus complex near Ostia, adding another $2.1 \mathrm{~km}$ of quay frontage, while the warehouses around Ostia were augmented to provide an estimated $31,882 \mathrm{~m}^{2}$ of total floorspace for all the incoming cargo (Keay 2012, p. 43).

\section{Circulatory Infrastructure}

The most obvious forms of infrastructure tend to be circulatory, and as the name suggests, they facilitate the dissemination and transport of people, animals, goods, resources, waste, and information. Common varieties include roads, canals, bridges, railways, aqueducts, viaducts, drains, sewers, causeways, and power grids. In fact, many general definitions of infrastructure (e.g., Larkin 2013) focus exclusively on such circulatory networks. Fundamentally, circulatory infrastructures are entities that remain immobile, so that other things can move. As a basic principle then, there is an inverse relationship between the mobility of circulatory infrastructures and the things that they permit to circulate. To create the physical fabric of something like a road is therefore a task that involves reducing mobility. Anyone who has attempted to trek across a large expanse of sand will know that walking across a surface whose physical components are highly mobile is extremely tiring and inefficient. There are various ways in which this reduced mobility can be achieved, with the simplest highways being made just from tamped and flattened earth. However, the frequent passage of feet and wheels tends to be deleterious to vegetation, and the subsequent loss of plant roots increases the mobility of the soil-which is especially problematic in areas where rainfall is common, as tamped earth can quickly become (very mobile) mud.

In the modern world, the standard solution has been to use bitumen, the function of which is to bind the mineral particles of the road surface within a layer of hyper-viscous 
liquid (a by-product of petroleum distillation). An asphalted highway is superior to a dirt road precisely because particles embedded within bitumen are much less mobile than those in an unsealed highway. The less the particles of the road surface are able to move, the faster, smoother, and more efficient will be the transport of things across the road surface. Ancient highways did not use bitumen, since it only became available as a bulk product during the modern era of fossil fuels. However, stone masonry was a very common means of reducing the mobility of a road surface in the ancient world. There are various ways of keeping the stones of a roadbed relatively fixed in place - the Romans had cement at their disposal, while Inca roads would frequently incorporate more massive blocks along their edges, in order to hold in place the smaller stones of the center. For some modern forms of circulatory infrastructure, excess mobility is not simply inefficient but potentially disastrous. Consider railroads as an example - even a relatively slight deviation of the rails from their proper position and alignment can have catastrophic consequences.

It is also worth noting than many circulatory infrastructures are in fact comprised of more than one kind of circulation system. For instance, roads usually have a transformative effect upon the hydrology of the regions they traverse, and so most highway networks include an integrated drainage system. Since roads are seldom placed along the highest topographic line on any given landscape, they will nearly always experience some degree of water runoff, which depending on its intensity, can be an impediment to travel, and can also damage the structure of the road. By managing the flow of water across the road, via side ditches and transverse channels, one is able to better facilitate the movements of people, animals, and things along the road. This is therefore a case where the functions of one circulatory system (i.e., roads) are supported by a secondary circulatory system (i.e., drainage channels) with which it is integrated. Transport canals offer a slightly unusual case, since they are essentially "flooded roads," where the water flow facilitates movement rather than impedes it. Essentially a canal is a form of infrastructure where the buoyancy of the water is used to transport heavy goods, reducing the need for energy inputs from humans or animals. Rivers are similarly useful for transport, but there is always a strong directional bias on a natural waterway, since the current will make it much harder to go upstream as compared to downstream. The extent of the bias depends on the strength of the current of course; on the tributaries of the Upper Amazon for instance, upstream canoeing is around four times slower than trying to cover the same downriver distance. Canals do have a current, but it is normally regulated through a series of locks or dams, and canalized water flows in a more controlled and slower fashion than in a typical river-largely eliminating the directional bias seen in a natural drainages. So even in cases where the "road surface" is a fluid, reduced mobility is still central to realizing its basic function.

Circulatory infrastructures tend to be extremely linear in shape, often resembling criss-crossing webs in their overall plan. This fact has certain "political" implications, insofar as circulatory infrastructures are typically extremely vulnerable to disruption by human agents. As a child growing up in Northern Ireland, I remember this fact being repeatedly underscored every time paramilitaries would seek to disrupt the cross-border railway traffic between Belfast and Dublin; usually by planting a bomb on the line, or making a false report of such to the police. Even with all the surveillance capabilities of a modern industrialized state, maintaining circulatory infrastructures in a region that is politically contested or unstable can be a very difficult task. In part, this is because of 
the extreme linearity of circulatory infrastructures, which makes them difficult to monitor and protect, so that even a small number of motivated persons can easily damage them. Moreover, the effects of sabotage are exacerbated in ways that are not seen in other kinds of infrastructure. In other words, circulatory infrastructures have high levels of system-wide interdependency, where damage to one area disrupts other sectors to a high degree. If there are a hundred storehouses, and someone deliberately destroys the wall of one storehouse, the other 99 structures can continue to function effectively. Whereas if someone destroys just one railway segment the entire line is compromised, and potentially the entire network as well, depending on how strategic was the damaged portion.

One way to understand this relative fragility of circulatory infrastructures is to see them as highly "networked" entities. The concept of the "network" is now a ubiquitous one, not just in archaeology, but in modern life generally. Thus, most recent scholarly attempts to define infrastructure directly appeal to the idea that it entails some sort of network. Larkin's (2013, p. 328) oft-cited essay is a clear example, where he suggests that infrastructures "....are built networks that facilitate the flow of goods, people, or ideas and allow for their exchange over space," while Hauser's (2015, p. 603) more economical definition sees infrastructure in similar terms, as "networks made material." However, the difficulty with the word "network" is that it has become so allencompassing as to have virtually no conceivable limits. For instance, in the theoretical terms of writers like Latour (e.g., 2005), literally everything that exists is a part of a "network." In certain iterations of new materialist theory then, networks are less a specific kind of thing, and more the fundamental basis of reality. I therefore prefer to use the term network here in a more restrictive sense to refer to apparatus that exhibit extremely high levels of system-wide integration and interdependency.

Per this definition, not all infrastructures are necessarily networks. Circulatory infrastructures usually are, but others (such as static infrastructures) are not, and these non-networks I would instead describe as "compound" structures (see Fig. 2). Compound structures are those comprised by lots of autonomous, repeating, discrete, and similar units - like the eyes of an insect. By contrast, networked structures are those based on a single, integrated system - like the eyes of a mammal. Static infrastructures, such as storehouses and agricultural terraces, are typical examples of compound structures. The different units are related to each other, but they are not integrated into a single interdependent system. Like an insect's eye, they are comprised by many repeating and similar blocks, with comparable functions and structures. Indeed, compound structures typically have a cellular or honeycomb-like appearance when seen in plan view. Circulatory infrastructures are quite different in that they form an integrated whole, where each component depends heavily on all the others, rather than simply duplicating them. The distinction I am drawing here is especially important when we consider the consequences of damage or disruption. For example, it is common for an interruption to one small part of an electricity grid to knock out whole swathes of the network - whereas if the wall of one agricultural terrace were to collapse, its impact on all the other terraces is usually negligible. Thus compound structures (including compound infrastructures) tend to suffer damage in a way that is localized, whereas damage to circulatory structures is necessarily systemic. This is precisely why circulatory infrastructures are so fragile when they encounter political environments that are unfriendly to them. 
Compound Structure

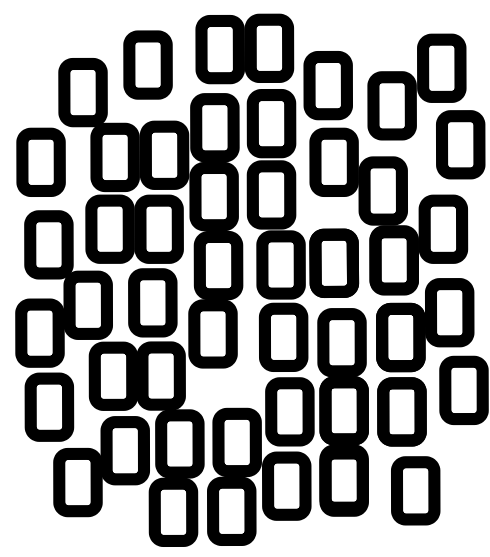

Networked Structure

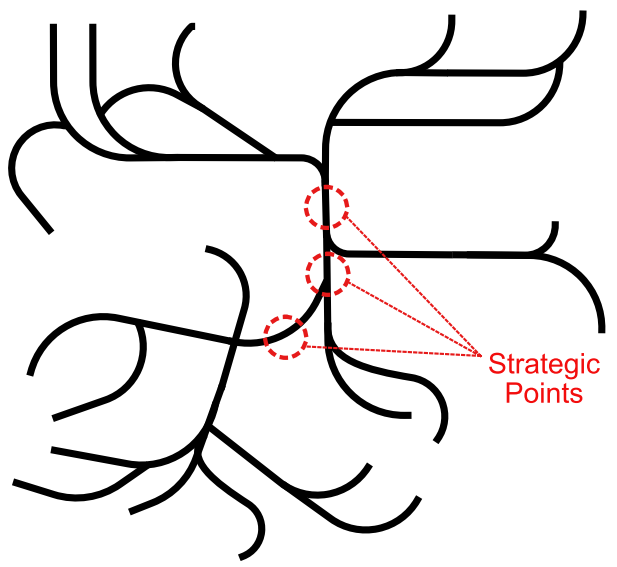

Fig. 2 A schematic representation of a compound structure (left) and a networked structure (right)

Although circulatory infrastructures are always highly interdependent and easily disrupted, it should still be acknowledged that some parts are usually more vital than others. In other words, damage to some sections of a network will have greater systemic repercussions than damage to certain other sections. It is said that when war is declared, the first casualty is the truth; but the second is probably bridges. Circulatory infrastructures generally have strategic points, by which we really mean they have vulnerable points. In any circulatory network, there are many possible routes that could be taken while journeying across it. And the greater the number of possible routes that must pass through a particular point, the more strategic it is. Or put in more negative terms, the more strategic a point is, the more possible transit routes will be affected by its disruption. This is effectively why the blockage of a major artery is more serious than a capillary, because a higher number of circulatory routes intersect with it. The principle here is the same, whether we are talking about the thoroughfares in the human body or a road network. The most vulnerable points on roads are almost always bridges, because they facilitate movement across a portion of the landscape that would otherwise present a substantial hurdle - and as a consequence, large numbers of routes converge on them. In targeting bridges during a military conflict, one is able to achieve maximum disruption for minimum effort. Indeed, destroying a single bridge can sometimes do a lot more damage to the enemies supply chains than destroying a hundred storage depots. This sort of interdependency (and consequent vulnerability) is a general feature of all circulatory infrastructures, meaning they do not survive for long where there is a lack of political stability or consensus.

These observations have some important implications for how we interpret the archaeological remains of ancient states and complex polities. For example, the appearance of major road-building projects is something that we see in ancient China from the Qin Dynasty onwards, which had an official highway network reaching some $6800 \mathrm{~km}$ in total length (Li 2013). Although earlier polities such as the Late Shang or the Zhou were highly "complex" (that is, urbanized and hierarchically organized), they still do not seem to have produced large-scale circulatory infrastructures within their domains of influence. Probably this was because, as Campbell (2009, p. 836) puts it, 
"Shang practices of authority... operated in limited and frequently indirect networks over a fractious landscape," in an environment defined by "constant warfare." Indeed, it is probably no coincidence that the ancient states with the most extensive road systems of all (i.e., the Roman and Inca empires) were ones that during their mature phases mostly waged warfare along their frontiers (rather than internally), and which maintained relatively continuous and uninterrupted control over their subject provinces. ${ }^{6}$ The pax romana and the pax incaica were environments in which massive circulatory infrastructure projects could be conceived and realized, in stark contrast with the warring and constantly fluctuating hegemonies exercised under the Late Shang or the Roman Republic.

Whereas static infrastructures are broadly linked to processes of intensification, for circulatory infrastructures the situation is more complicated. Certain kinds of circulatory networks do have a close relationship to agricultural intensification, especially in cases where they are directly integrated into static forms of infrastructure - one major example being agricultural terraces that incorporate irrigation channels. Yet as I have discussed, the quality of the political environment is an extremely important factor when it comes to explaining the overall scale of circulatory infrastructures; not just the traditional sliding-scale indices of "complexity" (e.g., hierarchy, centralization, and urbanization). In particular, circulatory infrastructures are nurtured in political environments characterized by high levels of stability, and with only limited incidences of insurgency or factional conflict. Consider the case of the stone causeways (called sacbeob) that were a major form of transport infrastructure in the classical Maya polities of the Yucatán. These causeways seldom extended very far beyond the cities that sponsored their construction. At the Classic Maya center of Caracol for example, recent survey work using LIDAR has revealed an associated $75 \mathrm{~km}$ causeway network, yet these thoroughfares run no more than 5-10 km beyond the urban core (Chase et al. 2011). As a rule, most Maya causeways are relatively short and seldom extend more than $3.5 \mathrm{~km}$ in length. Even the few longer causeways that connect regional centers only run for $10-30 \mathrm{~km}^{7}$ (Shaw 2001). Because the Yucatán was never unified into a single prehistoric polity, no pan-peninsular transport network ever existed and its circulatory infrastructures thus reflect a long-term regional tendency towards political fracture and disunity (Shaw 2001, pp. 268-269). As a result, nothing approaching the scale of the vast circulatory infrastructures of the Andean region was ever produced in pre-colonial Mesoamerica, despite the fact that the latter was generally much more urbanized.

\section{Bounding Infrastructure}

Bounding infrastructure regulates movements across landscapes, especially of people, animals, and water. It includes military barriers of all kinds, such as defensive walls, palisades, ramparts, moats, and booms. However, the portion of the built environment dedicated to martial activities is perhaps where the distinction between human-oriented

\footnotetext{
${ }^{6}$ This should not be taken to imply that the Inca and Roman empires were less warlike in general. Rather it points to a spatial bifurcation between "peaceful" internal provinces and "warring" exterior/frontier regions.

${ }^{7}$ The approximately 100-km-long causeway that connects the Maya sites of Coba and Yaxuna is exceptional in terms of length, and apparently unique (Shaw 2001).
} 
structures (i.e., architecture) and nonhuman-oriented structures (i.e., infrastructure) is at its most hazy. A defensive wall might be equally intended to stop things (e.g., arrows, cannonballs, and other projectiles), humans traveling in things (e.g., siege towers), and humans themselves (i.e., attackers on foot). A defensive tower or milecastle is perhaps more of an architectural entity, since it houses humans, but it is obviously part of the same structure as the wall into which it is set. Here we can only acknowledge that military structures are one of those cases especially prone to definitional ambiguity with respect to the infrastructure/architecture distinction.

Bounding infrastructure also covers obstacles used for the management of livestock, like fences and corrals. I have already discussed infrastructures that are designed to promote water flow (e.g., aqueducts and drains), but there are obviously a whole series of hydraulic systems that do the precise opposite. Infrastructures that work to impede water flow include dykes, seawalls, dams, levees, and weirs. Like their circulatory counterparts, bounding infrastructures are often highly linear features, and in topographic terms are either positive barriers (e.g., walls, ramparts, palisades, and fences) or negative barriers (e.g., moats, trenches, and ditches). In a sense, bounding infrastructures are the functional inverse of circulatory infrastructures; they block rather than promote movement. If circulatory infrastructures facilitate the movement of things longitudinally (i.e., in parallel to the linear direction), then bounding infrastructures impede movements that are transverse to the linear direction. In a sense, the difference between a bounding structure and a circulatory structure is therefore one of perspective. The very same linear structure can be bounding in one direction, yet circulatory in another. A good example of this is something like the Ming Dynasty incarnation of the Great Wall of China, which from the point of view of troops moving along its top is a road (and hence circulatory), whereas from the perspective of enemies seeking to move across it, it is a wall (and hence bounding). Similarly, irrigation ditches block water from flowing transversally, and in capturing surface runoff, they redirect the hydraulic flow so that it moves longitudinally instead.

Ultimately, the purpose of any bounding infrastructure is to make it difficult (i.e., slower and more energetically costly) to move across the barrier. In military situations, this has the obvious function of leaving an attacking force vulnerable to counter-assault while attempting to cross a defensive line. In livestock management contexts, barriers are more of an absolute constraint to the movement of the animals, which are usually physically incapable of overcoming the boundary. In practice however, bounding infrastructures do not simply impede movement, they also channel it through specific opening points. Every defensive wall has its gates, while every moat has a drawbridge or ferry. This channeling function is most clearly seen in the spectacular frontier barriers built by the great Eurasian empires of antiquity, such as Hadrian's Wall and the Great Wall of China. These ancient frontiers are often envisaged in older scholarship, and in the popular imagination still, as impenetrable barriers for keeping out hordes of "barbarians" (Crow 2004, p. 130). But this has never been a serious possibility. Virtually all fortified borders regulate movements (i.e., who crosses and where/when they cross), rather than completely impede them. Even in the modern world, highly patrolled and surveilled borders - like the one between the USA and Mexico-still permit millions of people to pass through on a regular basis, albeit with variable ease depending on their documents (McGuire 2013). Perhaps the only modern border that is close to being truly impassable is the Korean Demilitarized Zone; surely an extreme 
case. It would therefore be extraordinary if any ancient frontier had ever been absolutely impermeable.

Bounding infrastructure has a very deep antiquity. Depending on how one interprets the famous wall around the pre-Pottery Neolithic settlement at Jericho (Bar-Yosef 1986), the earliest archaeologically known fortifications may date back as far as $c a$. 8000 BC. Ultimately, for any highly mobile population, the best defense strategy is usually one of moving away from the threat. However, less mobile populations might feel more inclined to defend their homes and land, and defensive structures will therefore make sense in any context where you have both sedentary communities, and the potential for significant organized violence. This might explain why there is an emergence of walled settlements in many early Neolithic contexts (Parkinson and Duffy 2007). In some cases, rather than a small number of fortified settlements that acted as refuges during times of danger, we see a proliferation of forts across vast areas - something usually interpreted as indicating political "balkanization" and endemic (but generally small-scale) warfare. Classic examples include the hill-fort horizons of Iron Age Europe (Harding 2012; Redfern 2011) and the Andean Late Intermediate Period (ca. AD 1000-1450) (Arkush 2011; Arkush and Tung 2013; Covey 2008). Warfare is often discussed more in terms of quantity than quality-but rather than necessarily reflecting an absolute increase in belligerence, hill-fort horizons might be better understood to indicate contexts in which communities have come to habitually manage relations with their neighbors through violence, which in many cases may be highly ceremonialized. Unfortunately, talk of "ceremonial" or "ritual" warfare is often assumed to refer to less real, or merely symbolic, forms of conflict (see Arkush and Stanish 2005). Instead, such warfare should be understood as being governed by strict conventions and rules that all sides observe, with no implications as to the actual body count. It is noteworthy that hill-fort horizons are often coterminous with zones of similar material culture (including iconography), something that would fit with having shared customs that regulate inter-group combat. ${ }^{8}$

We might expect fortified settlements to generally precede the appearance of true forts, where the latter is defined as a bounded site occupied by a dedicated garrison of specialized "military" personnel who are dependent on the main population. At least this appears to have been the case for Mesoamerica and the Near East, although not necessarily for Europe, where a good number of early Neolithic defensive enclosures were seemingly not associated with settlements ${ }^{9}$ (Parkinson and Duffy 2007). But there is no reason to expect a general trajectory from fortified settlements to specialized military strongholds. In the case of Mesoamerica, major fortified settlements are in evidence from the end of the Early Preclassic. In Oaxaca, for example, the site of San José Mogote was defended by a palisade built sometime around $1300 \mathrm{BC}$; the earliest known fortified site in the region (Flannery and Marcus 2003). Yet even in much later periods, there is only limited evidence for specialized forts in Mesoamerica. Palisade and moat defensive systems seem to have proliferated in parts of the Maya region during the late Classic, such as in the Petexbatun from AD 760 onwards (Demarest

\footnotetext{
${ }^{8}$ The Iron Age hillfort horizon in Europe is broadly coterminous with the distribution of La Tène art styles, for instance.

${ }^{9}$ The non-settlement enclosures of Neolithic Europe do not appear to be true forts either, since they also lack evidence of internal garrisons. At present their function remains unclear.
} 
et al. 1997). However, almost all of these defensive barriers were associated with monumental centers and villages, rather than true forts. The only defensive site in the Petexbatun intended for a specialized military garrison seems to have been Cerro de Cheyo, located only a kilometer from the major center of Aguateca and probably constructed to protect water resources within its immediate agricultural hinterland (Demarest et al. 1997, pp. 243-245). This observation makes sense when we consider the relatively small scale of most Mesoamerican polities, despite their often highly developed urbanism. ${ }^{10}$ Even the Aztec State, the maximal polity of pre-colonial Mesoamerica, made only limited use of specialized fortifications with dedicated garrisons (Hassig 1995, pp. 259-261). By any definition, late prehistoric Mesoamerica was clearly home to considerable social complexity, and yet it retained a broadly "Neolithic" pattern of fortified settlements as opposed to true forts. Such infrastructure thus reflects the qualities of the broader socio-political environment, rather than following any predetermined sequence of evolutionary development.

One context where specialized fortifications appeared fairly quickly was ancient Egypt, where the earliest such evidence comes from the late predynastic period (Mumford 2010, p. 344). In this respect, it is probably no coincidence that Egypt was organized into a single territorial state from an unusually early stage (Trigger 1993, pp. 10-11). Under the Middle Kingdom and New Kingdom, specialized forts became far larger and more elaborate, especially along the Nubian frontier to the south (Morris 2005). Even relatively large territorial states and empires typically used strings of hardened strongholds to secure their border regions, rather than the continuous "great walls" of the kind associated with the Romans and the imperial Chinese. The Incas, for example, never built walls along their frontiers, although in some border regions - such as Ecuador - the density of fortifications could still be considerable (Bray 1992). In comparative terms then, the great wall phenomenon is a peculiar feature of the massive agrarian empires that emerged in Eurasia during the 1000-year period between the Third Century BC and the Seventh Century AD.

The Great Wall of China was begun by the Qin Dynasty (221-206 BC), initially reaching $4160 \mathrm{~km}$ in overall length ( $\mathrm{Li} \mathrm{2013,} \mathrm{pp.} \mathrm{246-247),} \mathrm{and} \mathrm{was} \mathrm{repeatedly} \mathrm{rebuilt}$ by successor dynasties over the subsequent 1800 years (albeit on different footprints). The Great Wall of Gorgan was the Persian equivalent, reaching just under $195 \mathrm{~km}$ in length and constructed on the eastern side of the Caspian Sea by the Sasanian Dynasty, likely sometime around the early Sixth Century AD (Nokandeh et al. 2006). At least for the Persian and Chinese cases, we know that the threat posed by confederations of steppe nomads was one fundamental rationale for these massive constructions. The Roman versions were the walls of Hadrian and Antoninus Pius in northern Britain, constructed during the Second Century AD and running 117.5 and $63 \mathrm{~km}$, respectively (Hingley 2012). The Romans also developed fortified frontiers (or limes) throughout their Eurasian and North African territories, although they were highly variable in form, sometimes making use of rivers as natural barriers, while on other occasions constructing segments of walls, ditches, and ramparts over $30 \mathrm{~km}$ in length (Symonds 2018). All

\footnotetext{
${ }^{10}$ Mesoamerican complex societies seem to have generally taken the form of city-states, which as a rule controlled polities that seldom extended beyond a $60-\mathrm{km}$ radius from their monumental centers. Even the later Mesoamerican empires were primarily "hegemonic" in form, with limited attempts to directly control large territories, and where the pre-imperial city-states remained the foundation of political life. For a useful synthesis of prehistoric polity size and structure in the region, see Chase et al. (2009).
} 
of these massive fortified lines probably fulfilled an ideological function at least as important as their roles in regulating movements of people and deterring military incursions. With respect to the relationship between bounding infrastructure and the state, they represent an interesting historical shift from fortified points in a landscape to a desire to comprehensively fortify entire landscapes themselves. At one level this reflects a major jump in the labor capacity of ancient polities, but it also owes much to the development of moral and political distinctions between "civilization" and "barbarism." Many states are expansionistic and perhaps all are necessarily ethnocentric to some degree, but the ambition to create a "universal empire" is a feature of a much more particular kind of polity (Bang and Kolodziejczyk 2012). Such claims to unlimited sovereignty were certainly explicit within the Roman, ancient Chinese, and Persian official ideologies, and we might thus see their "great walls" as a material manifestation of such worldviews.

Albeit on a smaller scale, it was also not unusual for the medieval states of the North Sea region to build their own large linear fortifications. These included Offa's Dyke, attributed to the Anglo-Saxon kingdom of Mercia in the Eighth Century AD. It was built along the border with the Welsh kingdom of Powys and the core earthwork ran continuously for approximately $103 \mathrm{~km}$ (Hill 2000). The Danevirke is a similar rampart-palisade structure some $35 \mathrm{~km}$ long, built by the early medieval polities of what is now Denmark after AD 700 (Dobat 2008). These are surprisingly large diversions of resources for states that would have been relatively modest in their scale and labor capacity. Given that these medieval walls were located in regions that were fairly close to the old Roman frontiers, their existence perhaps owes much to the ongoing memory and physical endurance of their ancient counterparts. As Tyler (2011) discusses, Anglo-Saxon historical sources show a clear conceptual link between the building of large linear barriers and the Roman emperors - meaning that for early medieval rulers, initiating such projects was a way to cast themselves in the grand mold of the Caesars. A quite different great wall tradition is also seen in West Africa during the late pre-colonial era. In particular, massive earthen ramparts were constructed within and around many Yoruba and Hausa sites between the Thirteenth and Nineteenth Centuries AD (Usman 2004). By far the grandest iteration was the many walls of Benin City, forming a set of huge agglutinated compounds and reaching a cumulative linear length of around 16,000 km (Connah 2015). These walls were partially defensive, but clearly also had important roles in demarcating social space (especially between royals and commoners) and functioned as monumental expressions of authority. A similar phenomenon is seen farther south in the approximately 200 sites of the Zimbabwe Tradition, albeit built in stone instead of ramped earth (Chirikure and Pikirayi 2008). I raise these examples here in order to highlight the degree to which infrastructure can be ideologically charged, acting as a focus for public ritual and political rhetoric. Although such matters have not been the main focus of this article, this is certainly not meant to imply that they are unimportant aspects of infrastructural projects.

\section{Signaling Infrastructure}

I do not plan to dwell too much on the topic of signaling infrastructure, mainly because its relevance to periods prior to the last hundred years is fairly limited. Signaling 
infrastructure essentially refers to any apparatus that uses electromagnetic energy as a means of "at-a-distance" communication. Lighthouses are probably the most common example of this technology in the ancient world - the monumental Pharos of Alexandria being by far the most famous instance, built under the Ptolemaic Dynasty in the Third Century BC. For earlier periods, we can probably assume that signal fires would have been used on a less formal basis to guide ships, even if true lighthouses were an invention of the Hellenistic Period. While modern lighthouses are particularly important in drawing a crew's attention to hazardous stretches of coastline, the ancient version was primarily a means to inform ships of the precise location of a particular harbor (Blackman 1982). Although less common, there are also terrestrial versions of signaling infrastructure, which were generally intended to raise the alarm against more human threats (e.g., invasions and insurrections). For example, the seventeenth-century Andean chronicler Vega (2006 [1609], p. 45) claimed that the Incas made use of a firebased signaling system so as to warn the imperial elites of urgent military threats in regions outside the imperial capital. Interestingly, a recent study by Lee (2010) has potentially identified the archaeological remains of the network of signaling stations that would have comprised this early warning system. Fire-based signaling beacons were also used along the fortified borders of the major Eurasian empires, such as the Roman frontier in northern Britain (Murphy et al. 2018).

Since the early Twentieth Century onwards, signaling infrastructures have proliferated enormously, initially in the form of radio transmitters, and most recently as cellphone towers. In modern times, we have clearly seen a massive increase in the complexity of the information that is capable of being transmitted, alongside an expansion of the parts of the electromagnetic spectrum that are used. Whereas ancient forms always relied upon the visible portion of the light spectrum, radio waves and microwaves have now become extremely important. One consequence of this shift is the need for specialized receiving devices, whereas ancient versions relied entirely upon the human eye. That said, we should not ignore the continued importance of traditional light-based signaling infrastructures, traffic lights being the obvious and now globally ubiquitous example. And here we might note that in terms of its physical shape, both ancient and modern signaling infrastructure almost always entails some sort of turriform structure. Although perhaps the key characteristic is simply elevation above the terrestrial surface, something that telecommunications satellites take to its logical extreme.

Finally, signaling infrastructure should not be conflated with communications infrastructure in general. After all, one of the things that circulatory infrastructure permits to flow is information, whether that takes the form of an Inca runner carrying a khipu communiqué along the imperial road network, or an undersea electric cable carrying a telegram (both of which, incidentally, work through binary encoding). With circulatory infrastructure, information-like anything else - is carried longitudinally along the body of the physical infrastructure itself (e.g., along the road, or through the telegraph wire). By contrast, signaling infrastructures always transmit information "at-a-distance," requiring no such linear structures to act as material conduits for its conveyance. In short, communication via circulatory infrastructure requires a physical medium for transmission, whereas communication via signaling infrastructure does not. 


\section{The Limitations of Typology}

Some general remarks are necessary with respect to the typology just outlined above. First, it should be emphasized that the different forms of infrastructure seldom exist in pristine isolation from each other. Indeed, in reality they are often closely intertwined and highly interdependent. For instance, a harbor - meaning the reinforced basin of water in which ships are moored - is a form of static infrastructure. But most major harbors will have associated port facilities, including dockside warehouses (another form of static infrastructure) that will likely be integrated with piers, jetties, and canals (i.e., circulatory infrastructure). Many harbors might also include one or more lighthouses to guide ships (a form of signaling infrastructure). A port/harbor then is not really one kind of infrastructure, so much as a convergence of several different kinds, all operating together, and with each fulfilling different, often multiple, goals. Similarly, agricultural terraces (meaning the consolidated masses of stepped soil) are themselves static infrastructures, but are very often integrated with irrigation or drainage channels, which are a form of circulatory infrastructure.

Second, not only are the different infrastructural taxa frequently interwoven in practice, the categories themselves are not necessarily mutually exclusive. The earlier example of the Ming-era Great Wall of China, which served as a road for troops moving along the wall, while simultaneously creating a barrier across the steppe frontier, illustrates that in some cases a particular infrastructural apparatus will fall into more than one taxon - in this instance, simultaneously fulfilling both circulatory and bounding functions. A similar, albeit much more recent example is seen in the Hoover Dam, located in the Southwestern United States. The dam obstructs the flow of the Colorado River, thereby creating Lake Mead, but its crest also functioned as a major road (i.e., Route 93) for almost three-quarters of a century. Nonetheless, we cannot deny the basic materiality of such entities. The fact that bounding and circulatory infrastructures are both highly linear makes them particularly amenable to being manifest in the same physical entity. By contrast, it is difficult to imagine how a signaling tower could simultaneously act as a road.

Third, the typology I have presented places the emphasis on the purposes for which infrastructures are designed - although this does not necessarily mean their "original" design. Infrastructures are often repurposed, and to construct a typology based on any artifact's design characteristics is not to negate its real history of use. Indeed, should an artifact be physically altered so that it comes to fulfill quite different purposes from those originally intended, we might say that it has been redesigned to such an extent that it has effectively become a different thing. A good (contemporary) example of this is the High Line in New York City, a 2.33$\mathrm{km}$ long section of viaduct that was reconstructed as an urban park in 2009. With the removal of its railway tracks, and the addition of soil and plants, the High Line ceased to function purely as a piece of circulatory infrastructure-it does still have walkways for human visitors, so this purpose persists albeit in a very different fashion. Now it also functions as a kind of static infrastructure, accommodating a considerable volume of soil, much like a more traditional agricultural terrace. Of course, diachronic analysis is a basic feature of all archaeological research, and taxa are regularly used as heuristic devices to make sense of how entities change. So, just as someone might trace the material transformation of a settlement from a 
"village" into a "city," we can also follow how, over time, infrastructures shift from one form into another.

On a related point, one should always be attentive to both the intended and actual uses of any item of material culture, however large or small. I have already mentioned that for marginalized communities, common forms of circulatory infrastructure like subway tunnels and underpasses often serve as residential spaces (i.e., as architecture). Providing shelter for homeless people is certainly not a common goal of transport infrastructure, at least from the perspective of planning authorities, who typically disapprove of such uses. Through what is called "hostile" or "defensive" architecture, urban infrastructures are therefore increasingly being adapted to counteract such unplanned uses. For instance, the use of timed water sprinklers in public spaces where there are no plants; the purpose of which is to discourage rough sleeping (Petty 2016, p. 74). Yet even though artifacts often fulfill purposes that were not originally foreseen, we cannot discount the importance of design processes in shaping their life histories. The material characteristics of an artifactual entity enable certain uses and impede others, despite the fact that not all uses are necessarily anticipated. For example, a hammer might have been designed primarily to hit nails, but the possibility of using it as a weapon is always latent within it. Yet the hammer cannot be used as a cutting device, because its material form conflicts with that purpose (i.e., it lacks a suitable edge). For it to operate it as a cutting tool it would have to be redesigned (i.e., remade) in such a way that it would cease to be an effective hammer.

Through the processes of design and redesign, purposes are congealed within artifacts (which includes unintended purposes). We should not therefore think of "design" as something that ends, or as necessarily occurring prior to manufacture. In reality, design is an ongoing and interactive process, and is central to all human engagement with material culture. Because infrastructures are often so large and complex, they are perhaps particularly subject to redesign and modification over time. Moreover, design is not destiny, and it is always interesting to look at the interaction between an object's planned and actual uses.

The aim of a good typology is ultimately to make sense of our assemblages, rather than straightjacket our thinking about them. One can describe an excavated artifact as either a tool or a weapon-but weapons are a kind of tool, and virtually any tool could be used as a weapon - thus these categories are not absolute, nor without a degree of blurriness. Nonetheless, many archaeologists will still find it useful to delimit part of an assemblage as "weaponry," because the intentionality and design that gave rise to an artifact still matters. We would surely lose something if we were to bundle the swords in with all the hammers, tongs, and cleavers simply because the category "weapon" is not absolute. Infrastructures are also intentional artifacts (albeit on a much larger scale), and so it is therefore useful to categorize them in ways that reflect their intended purposes. There is always a danger of essentialism when deploying a typology, but the response to this is not to abandon typologies; rather we should insist that they always remain heuristic (and thus perpetually provisional) constructs. Thus, the taxonomy I have outlined is explicitly intended to be non-exclusive (i.e., the same thing can fall within multiple categories simultaneously) and dynamic (i.e., the original purposes are not privileged over later ones, in recognition of the fact that things undergo physical change and transformation). 


\section{Conclusions}

In my outline of a basic definition of infrastructure, I argued that neither the state nor urbanism was a necessary prerequisite for its existence. Similarly, infrastructure does not have a simple relationship to urbanism or any other index of "complexity." In particular, there is little evidence for a general evolutionary trajectory for infrastructure, and different regions and time periods appear to offer their own distinctive patterns. Although there are important relationships between infrastructure and the phenomena we traditionally associate with socio-political complexity, they cannot be reduced to straightforward correlations. Take urbanism for example. In the ancient Roman and (post-Qin) Chinese empires, the scale of infrastructural projects (especially roads, walls, and canals) seems to have increased hand-inhand with the growth of cities, whereas in the Americas quite different patterns are visible. So in Mesoamerica, the scale of urban centers continues to increase until the colonial period (culminating in Tenochtitlan), and yet there is no concomitant expansion of infrastructure; certainly not beyond the immediate environs of the urban cores. In the Andes however, the spatial scale of late prehistoric infrastructural projects was exceptional, and yet without any appreciable increase in urbanism at the same time. Exploring how infrastructure relates to other indices of complexity like urbanism and hierarchy would thus seem to offer an interesting area for future research; especially since the patterns we see are quite variable. Indeed, it appears there is little justification for a teleological account of infrastructure, and the four types I have discussed should certainly not be regarded as "phases" or as having any sort of evolutionary relationship to each other.

During my typological discussion of infrastructure, I also offered some commentary on the earliest manifestations of the different kinds of infrastructure in various parts of the world; how they changed over time, and how they might relate to different socio-political contexts. Admittedly this commentary was nowhere close to a comprehensive account. A truly exhaustive survey of infrastructure across every continent and encompassing multiple millennia would be a task requiring many volumes. I also write from the point of view of an Andean specialist, and so my knowledge is inevitably circumscribed by my regional bias. But I do hope to have offered a convincing argument that the comparative study of infrastructure across space and time is a worthwhile archaeological aim. Again I draw my inspiration from other, more deeply interrogated categories like urbanism, taking the view that no comparative project can proceed properly without a basic theoretical framework as a starting point. Admittedly, the archaeological literature on urbanism has produced no consensus, and remains an arena for much debate and contestation. But the aim of this article has not been to predetermine interpretations, so much as to try to put the topic of infrastructure firmly on the archaeological agenda — not to provide answers, but to prompt new questions.

Acknowledgements The financial support of the Leverhulme Trust (ECF-2016-618) and the University of Cambridge is gratefully acknowledged. Adam S. Green provided valuable feedback on an earlier draft of the manuscript, as did three anonymous reviewers. All errors remain my own.

Open Access This article is distributed under the terms of the Creative Commons Attribution 4.0 International License (http://creativecommons.org/licenses/by/4.0/), which permits unrestricted use, distribution, and reproduction in any medium, provided you give appropriate credit to the original author(s) and the source, provide a link to the Creative Commons license, and indicate if changes were made. 
Publisher's Note Springer Nature remains neutral with regard to jurisdictional claims in published maps and institutional affiliations.

\section{References}

Anand, N. (2012). Municipal disconnect: on abject water and its urban infrastructures. Ethnography, 13(4), 487-509.

Arkush, E. (2011). Hillforts of the ancient Andes: Colla warfare, society, and landscape. Gainesville: University Press of Florida.

Arkush, E., \& Stanish, C. (2005). Interpreting conflict in the ancient Andes: implications for the archaeology of warfare. Current Anthropology, 46(1), 3-28.

Arkush, E., \& Tung, T. A. (2013). Patterns of war in the Andes from the Archaic to the Late Horizon: insights from settlement patterns and cranial trauma. Journal of Archaeological Research, 21(4), 307-369.

Bang, P. F., \& Kolodziejczyk, D. (2012). Elephant of India': universal empire through time and across cultures. In P. F. Bang \& D. Kołodziejczyk (Eds.), Universal empire: a comparative approach to imperial culture and representation in Eurasian history (pp. 1-40). Cambridge: Cambridge University Press.

Bar-Yosef, O. (1986). The walls of Jericho: an alternative interpretation. Current Anthropology, 27(2), 157162.

Blackman, D. J. (1982). Ancient harbours in the Mediterranean. Part 2. International Journal of Nautical Archaeology, 11(3), 185-211.

Bogaard, A., Charles, M., Twiss, K. C., Fairbairn, A., Yalman, N., Filipović, D., Demirergi, G. A., Ertuğ, F., Russell, N., \& Henecke, J. (2009). Private pantries and celebrated surplus: storing and sharing food at Neolithic Çatalhöyük, Central Anatolia. Antiquity, 83(321), 649-668.

Bray, T. L. (1992). Archaeological survey in northern highland Ecuador: Inca imperialism and the País Caranqui. World Archaeology, 24(2), 218-233.

Campbell, R. B. (2009). Toward a networks and boundaries approach to early complex polities: the Late Shang case. Current Anthropology, 50(6), 821-848.

Chase, A. F., Chase, D. Z., \& Smith, M. E. (2009). States and empires in ancient Mesoamerica. Ancient Mesoamerica, 20(2), 175-182.

Chase, A. F., Chase, D. Z., Weishampel, J. F., Drake, J. B., Shrestha, R. L., Slatton, K. C., Awe, J. J., \& Carter, W. E. (2011). Airborne LiDAR, archaeology, and the ancient Maya landscape at Caracol, Belize. Journal of Archaeological Science, 38(2), 387-398.

Chepstow-Lusty, A. J., Frogley, M. R., Bauer, B. S., Leng, M. J., Boessenkool, K. P., Caarcaillet, C., Ali, A. A., \& Gioda, A. (2009). Putting the rise of the Inca empire within a climatic and land management context. Climate of the Past, 5(3), 375-388.

Childe, V. G. (1950). The urban revolution. Town Planning Review, 21(1), 3-17.

Chirikure, S., \& Pikirayi, I. (2008). Inside and outside the dry stone walls: revisiting the material culture of Great Zimbabwe. Antiquity, 82(318), 976-993.

Connah, G. (2015). African civilizations: an archaeological perspective. Cambridge: Cambridge University Press.

Covey, R. A. (2008). Multiregional perspectives on the archaeology of the Andes during the Late Intermediate Period (c. AD 1000-1400). Journal of Archaeological Research, 16(3), 287-338.

Cowgill, G. L. (2004). Origins and development of urbanism: archaeological perspectives. Annual Review of Anthropology, 33(1), 525-549.

Crow, J. (2004). The northern frontier of Britain from Trajan to Antoninus Pius: Roman builders and native Britons. In M. Todd (Ed.), A companion to Roman Britain (pp. 114-135). Oxford: Blackwell.

D'Altroy, T. N. (2000). Andean land use at the cusp of history. In D. L. Lentz (Ed.), Imperfect balance: landscape transformations in the Precolumbian Americas (pp. 357-390). New York: Columbia University Press.

D’Altroy, T. N., \& Earle, T. K. (1985). Staple finance, wealth finance, and storage in the Inka political economy. Current Anthropology, 26(2), 187-206.

De La Vega, G. (2006[1609]). The royal commentaries of the Incas and general history of Peru. Cambridge: Hackett Publishing.

Demarest, A. A., O'Mansky, M., Wolley, C., Van Tuerenhout, D., Inomata, T., Palka, J., \& Escobedo, H. (1997). Classic Maya defensive systems and warfare in the Petexbatun region: archaeological evidence and interpretations. Ancient Mesoamerica, 8(2), 229-253. 
Dobat, A. S. (2008). Danevirke revisited: an investigation into military and socio-political organisation in South Scandinavia (c AD 700 to 1100). Medieval Archaeology, 52(1), $27-67$.

Elyachar, J. (2010). Phatic labor, infrastructure, and the question of empowerment in Cairo. American Ethnologist, 37(3), 452-464.

Elyachar, J. (2012). Next practices: knowledge, infrastructure, and public goods at the bottom of the pyramid. Public Culture, 24(1), 109-129.

Ertsen, M. W. (2016). 'Friendship is a slow ripening fruit': an agency perspective on water, values and infrastructure. World Archaeology, 48(4), 500-516.

Finucane, B. C. (2009). Maize and sociopolitical complexity in the Ayacucho Valley, Peru. Current Anthropology, 50(4), 535-545.

Flannery, K. V., \& Marcus, J. (2003). The origin of war: new 14C dates from ancient Mexico. Proceedings of the National Academy of Sciences, 100(20), 11801-11805.

Gould, R. A. (2011). Archaeology and the social history of ships. Cambridge: Cambridge University Press.

Guillet, D. (1987). Terracing and irrigation in the Peruvian highlands. Current Anthropology, 28(4), 409-430.

Harding, D. (2012). Iron Age hillforts in Britain and beyond. Oxford: Oxford University Press.

Harvey, P. (2012). The topological quality of infrastructural relation: an ethnographic approach. Theory, Culture \& Society, 29(4-5), 76-92.

Hassig, R. (1995). Aztec warfare: imperial expansion and political control. Norman: University of Oklahoma Press.

Hauser, M. W. (2015). The infrastructure of nature's island: settlements, networks and economy of two plantations in colonial Dominica. International Journal of Historical Archaeology, 19(3), 601-622.

Hill, D. (2000). Offa's Dyke: pattern and purpose. The Antiquaries Journal, 80(1), 195-206.

Hillam, J., Groves, C. M., Brown, D. M., Baillie, M. G. L., Coles, J. M., \& Coles, B. J. (1990). Dendrochronology of the English Neolithic. Antiquity, 64(243), 210-220.

Hingley, R. (2012). Hadrian's Wall: a life. Oxford: Oxford University Press.

Hodder, I. (2004). Theory and practice in archaeology. London: Routledge.

Jennings, J. (2016). Killing civilization: a reassessment of early urbanism and its consequences. Albuquerque: University of New Mexico Press.

Johnson, M. (2010). Archaeological theory: an introduction. Oxford: John Wiley \& Sons.

Johnson, M. (2013). What is theory for? In A. Gardner, M. Lake, \& U. Sommer (Eds.), The Oxford handbook of archaeological theory. https://doi.org/10.1093/oxfordhb/9780199567942.013.001.

Keay, S. (2012). The port system of Imperial Rome. In S. Keay (Ed.), Rome, Portus and the Mediterranean (pp. 33-67). London: British School at Rome.

Kim, J. (2014). From labour control to surplus appropriation: landscape changes in the Neolithization of southwestern Korea. Journal of World Prehistory, 27(3-4), 263-275.

Larkin, B. (2008). Signal and noise: media, infrastructure, and urban culture in Nigeria. Durham: Duke University Press.

Larkin, B. (2013). The politics and poetics of infrastructure. Annual Review of Anthropology, 42(1), 327-343.

Latour, B. (2005). Reassembling the social: an introduction to actor-network-theory. Oxford: Oxford university press.

Lee, V. (2010). Choquequirao to Machu Picchu at the speed of light: visual signaling among the Incas. Ñawpa Pacha, 30(1), 1-23.

Li, F. (2013). Early China: a social and cultural history. Cambridge: Cambridge University Press.

McGuire, R. H. (2013). Steel walls and picket fences: rematerializing the US-Mexican border in ambos Nogales. American Anthropologist, 115(3), 466-480.

Mitchell, T. (2014). Introduction: life of infrastructure. Comparative Studies of South Asia, Africa and the Middle East, 34(3), 437-439.

Morris, E. F. (2005). The architecture of imperialism: military bases and the evolution of foreign policy in Egypt's New Kingdom. Leiden: Brill.

Morrison, K. D. (2015). Archaeologies of flow: water and the landscapes of Southern India past, present, and future. Journal of Field Archaeology, 40(5), 560-580.

Mumford, G. D. (2010). Settlements - distribution, structure, architecture: Pharaonic. In A. B. Lloyd (Ed.), A companion to ancient Egypt (pp. 326-349). Oxford: Blackwell.

Murphy, K. M., Gittings, B., \& Crow, J. (2018). Visibility analysis of the Roman communication network in southern Scotland. Journal of Archaeological Science, 17, 111-124.

Nokandeh, J., Sauer, E. W., Rekavandi, H. O., Wilkinson, T., Abbasi, G. A., Schweninger, J. L., Mahmoudi, M., Parker, D., Fattahi, M., Usher-Wilson, L. S., \& Ershadi, M. (2006). Linear barriers of northern Iran: the great wall of Gorgan and the wall of Tammishe. Iran, 44(1), 121-173. 
Palus, M. M. (2010). Meaterialities of government: a historical archaeology of infrastructure in Annapolis and Eastport, 1865-1951. Doctoral dissertation, Columbia University.

Palus, M. (2011). Infrastructure and the conduct of government: annexation of the Eastport community into the City of Annapolis during the twentieth century. In S. K. Croucher \& L. M. Weiss (Eds.), The archaeology of capitalism in colonial contexts (pp. 269-293). New York: Springer.

Parkinson, W. A., \& Duffy, P. R. (2007). Fortifications and enclosures in European prehistory: a cross-cultural perspective. Journal of Archaeological Research, 15(2), 97-141.

Pauketat, T. R. (2007). Chiefdoms and other archaeological delusions. Lanham: Altamira Press.

Paulette, T. (2016). Grain, storage, and state making in Mesopotamia (3200-2000 BC). In L. R. Manzanilla \& M. Rothman (Eds.), Storage in ancient complex societies: administration, organization and control (pp. 85-110). New York: Routledge.

Pearsall, D. M. (2008). Plant domestication and the shift to agriculture in the Andes. In H. Silverman \& W. Isbell (Eds.), The handbook of South American archaeology (pp. 105-120). New York: Springer.

Petty, J. (2016). The London spikes controversy: homelessness, urban securitization and the question of 'hostile architecture'. International Journal for Crime, Justice and Social Democracy, 5(1), 67-81.

Philip, G. (2008). The Early Bronze Age I-III. In R. Adams (Ed.), Jordan: an archaeological reader (pp. 161226). London: Equinox.

Pluckhahn, T. J. (2010). Household archaeology in the southeastern United States: history, trends, and challenges. Journal of Archaeological Research, 18(4), 331-385.

Redfern, R. C. (2011, January). A re-appraisal of the evidence for violence in the late Iron Age human remains from Maiden Castle hillfort, Dorset, England. Proceedings of the Prehistoric Society, 77, 111-138.

Redfield, P. (2011). Cleaning up the Cold War: global humanitarianism and the infrastructure of crisis response. In G. Hecht (Ed.), Entangled geographies: empire and technopolitics in the Global Cold War (pp. 267-292). Cambridge: The MIT Press.

Robbins, B. (2007). The smell of infrastructure: notes toward an archive. Boundary 2, 34(1), $25-33$.

Sandweiss, D. H., \& Richardson, J. B. (2008). Central Andean environments. In H. Silverman \& W. Isbell (Eds.), The handbook of South American archaeology (pp. 93-104). New York: Springer.

Scarborough, V. L., \& Lucero, L. J. (2010). The non-hierarchical development of complexity in the semitropics: water and cooperation. Water History, 2(2), 185-205.

Schiffer, M. B. (1988). The structure of archaeological theory. American Antiquity, 53(3), 461-485.

Schnitzler, A. (2013). Traveling technologies: infrastructure, ethical regimes, and the materiality of politics in South Africa. Cultural Anthropology, 28(4), 670-693.

Schouten, P. (2013). The materiality of state failure: social contract theory, infrastructure and governmental power in Congo. Millennium, 41(3), 553-574.

Shaw, J. M. (2001). Maya Sacbeob: form and function. Ancient Mesoamerica, 12(2), 261-272.

Skarbø, K., \& VanderMolen, K. (2016). Maize migration: key crop expands to higher altitudes under climate change in the Andes. Climate and Development, 8(3), 245-255.

Smith, M. E. (2011). Empirical urban theory for archaeologists. Journal of Archaeological Method and Theory, 18(3), 167-192.

Smith, M. L. (2016). Urban infrastructure as materialized consensus. World Archaeology, 48(1), 164-178.

Snead, J. E., Erickson, C. L., \& Darling, J. A. (Eds.). (2009). Landscapes of movement: trails, paths, and roads in anthropological perspective. Philadelphia: University of Pennsylvania Press.

Star, S. L. (1999). The ethnography of infrastructure. American Behavioral Scientist, 43(3), 377-391.

Symonds, M. (2018). Protecting the Roman Empire: fortlets, frontiers, and the quest for post-conquest security. Cambridge: Cambridge University Press.

Tomášková, S. (2005). What is a burin? Typology, technology, and interregional comparison. Journal of Archaeological Method and Theory, 12(2), 79-115.

Trigger, B. G. (1993). Early civilizations: ancient Egypt in context. Cairo: American University in Cairo Press. Tyler, D. J. (2011). Offa's Dyke: a historiographical appraisal. Journal of Medieval History, 37(2), $145-161$. Usman, A. A. (2004). On the frontier of empire: understanding the enclosed walls in northern Yoruba, Nigeria. Journal of Anthropological Archaeology, 23(1), 119-132.

Wittfogel, K. A. (1957). Oriental despotism: a study of total power. New Haven: Yale University Press.

Yoffee, N. (2009). Making ancient cities plausible. Reviews in Anthropology, 38(4), 264-289.

Zheng, Y., Sun, G., Qin, L., Li, C., Wu, X., \& Chen, X. (2009). Rice fields and modes of rice cultivation between 5000 and 2500 BC in East China. Journal of Archaeological Science, 36(12), 2609-2616. 